\title{
Poesia, MITO E FILOSOFIA: UMA LEITURA INSISTENTE DE ORIDES FONTELA
}

POETRY, MYTH AND PHILOSOPHY: CLOSE READING OF

ORIDES FONTELA

Patricia Lavelle

Pontifícia Universidade Católica do Rio de Janeiro

Rio de Janeiro, RJ, Brasil

ORCID 0000-0002-7466-4999

\section{Resumo}

Com o objetivo de pensar as potencialidades da interface poesia/filosofia, examinarei o modo operatório da intertextualidade na produção poética de Orides Fontela. A partir da leitura insistente do poema "Kant (Relido)", em cuja fatura extremamente sintética identificamos não apenas a referência a uma passagem significativa da Crítica da razáo prática, mas também uma releitura do mito de Gaia e Uranos, relatado na Teogonia de Hesíodo, procurarei compreender o modo como a poeta dialoga com suas leituras, operando transformaçóes e deslocamentos consideráveis. Neste poema, como em outros, Orides Fontela não se contenta em dizer de outro modo as teses que o texto filosófico enuncia, transpondo-as alegoricamente, numa expressão poética, mas ela responde poeticamente à interpelação contida na teoria. Assim, sua obra nos leva a colocar a questão do pensamento poético.

Palavras-chave: Poesia e filosofia, Orides Fontela, mito

\section{Abstract}

This paper shows the inter-textual references in Orides Fontela's poetic production in order to think the potential of the interface poetry/ philosophy. A close-reading of the poem "Kant (Relido)", identifies not only an interesting deformation of a citation of the Critique of the practice raison, but also a re-reading of Gaia and Uranus myth related in Hesiod's Theogony. This paper shows the way the poet dialogue with her references, operating transformations and dislocations. The poem "Kant (Relido)" not only transposes allegorically the philosophical thesis in a poetic expression, but it answers poetically to the theoretical

\section{Résumé}

Ayant l'objectif de penser le potentiel de l'interface poésie/philosophie, cet article examine le mode opératoire des intertextualités dans la production poétique d'Orides Fontela. A partir de la lecture insistante du poème "Kant (Relido) " où, malgré sa facture très synthétique, nous identifions non seulement la référence à un passage significatif de la Critique de la raison pratique, mais aussi une relecture $\mathrm{du}$ mythe de Gaia et Uranus présenté dans la Théogonie d'Hésiode, je cherche à comprendre comment la poétesse dialogue avec ses propres lectures, opérant des transformations et des 
provocation of the philosophy. Orides Fontela's poetic work allows us to discuss the problem of the poetic thinking.

Keywords: Poetry and philosophy, Orides Fontela, myth. déplacements considérables. Dans ce poème, comme dans d'autres, Orides Fontela ne se contente pas de dire d'une autre manière les thèses présentées dans le texte philosophique, les transposant allégoriquement, mais elle répond poétiquement aux provocations contenues dans la théorie. Ainsi, son œuvre nous permet de poser la question de la pensée poétique.

Mots-clé: Poésie et philosophie, Orides Fontela, mythe.

Modo de relação com o espaço, o mito se caracteriza, segundo Cassirer ${ }^{1}$, por uma expressividade que apaga todo distanciamento entre a imagem e o que ela representa. Mediatizada pela linguagem, essa experiência radicalmente expressiva engendra uma infinidade de variaçóes, as vezes até contraditórias, de um mesmo tema ou personagem. Ora, se a poesia grega surge com o mito, alimentando-se de seu polimorfismo, ela se afasta de sua expressividade primeira através do movimento reflexivo inerente à representação artística. Trabalho no material polimorfo do mito, trabalho do mito no discurso, trabalho não mais expressivo, mas representativo, da arte poética, as epopeias constituem mito-logias. Mesmo que a poesia da Grécia arcaica esteja impregnada de valor cultual, e participe portanto do mundo do mito, ela introduz distanciamentos reflexivos no interior da imagem mítica.

É o caso, por exemplo, da Teogonia de Hesíodo, que antecipa as sistematizações cosmológicas dos pré-socráticos e, colocando em cena pela primeira vez o "eu” do poeta, indica a instância subjetiva da representação. Ao nomear a voz poética, este longo poema abre um caminho para a poesia lírica, que viria a se desenvolver um século mais tarde, mas também tem em comum com o pensamento teórico nascente uma preocupação de sistematização que implica uma crítica dos materiais míticos tradicionais.

Compreendido como relação expressiva ao espaço, o mito não está presente apenas nas culturas arcaicas, como a Grécia antiga. Essa forma simbólica não foi definitivamente ultrapassada no mundo contemporâneo, mais ainda coexiste com outros modos de relação com o sentido externo e,

1 Sobre a noção de mito em Cassirer, $c f$. Ernst Cassirer. "Espace mythique, espace esthétique et espace théorique" (tradução de Christian Berner), in: Ecrits sur l'art, Oeuves XII. Paris: Cerf, 1995 e "Le problème du symbole et le système de la philosophie" (tradução de Éric Dufour), In: Marc de Launay (org.) Néo-kantismes et théorie de la connaissance. Paris: Vrin, 2000. 
em particular, com a modalidade estética de representaçáo. Talvez por isso a poesia mais contemporânea não cesse de trabalhar e retrabalhar materiais míticos legados pela tradição literária clássica.

Em Orides Fontela (1940-1998), cuja obra completa foi reeditada e publicada em $2015^{2}$, o trabalho poético sobre estruturas míticas dialoga de perto com o conceito. Assim, sua produçáo leva-nos a perguntar como uma poeta contemporânea opera deslocamentos nos materiais míticos, incitandonos a localizar a questão sobre o pensamento poético entre a forma simbólica do mito e a da teoria. Parece-me, sobretudo, que tal interrogação náo deve ser colocada abstratamente, de maneira estritamente conceitual, mas que concerne, a cada vez, a um corpus textual singular. Pois, mesmo que possamos pensar um modo poético de relação, ou a poesia como forma simbólica, não existe um único pensamento poético que se materializaria em todos os poemas, mas uma pluralidade de reflexóes que se constituem em obras poéticas individuais.

Assim, para evitar operar abstratamente, seguirei uma sugestáo metodológica de Jean Bollack e proporei uma "leitura insistente" 3 . Lerei, portanto, de maneira insistente, um poema de Orides Fontela que se apresenta igualmente como leitura, isto é, como uma releitura de uma passagem da Crítica da razão prática. A partir da leitura insistente do poema "Kant (Relido)", em cuja fatura extremamente sintética identificamos não apenas a referência a uma passagem significativa da Crítica da razáo prática, mas também uma releitura do mito de Gaia e Uranos, relatado na Teogonia de Hesíodo, procurarei compreender o modo como a poeta dialoga com suas leituras, operando transformaçóes e deslocamentos consideráveis. Assim, minha leitura insistirá não apenas numa breve análise da materialidade rítmica do poema, mas sobretudo numa reconstrução das intertextualidades que o atravessam e nele dialogam.

Neste poema, como em outros, Orides Fontela não se contenta em dizer de outro modo as teses que o texto filosófico enuncia, transpondo-as alegoricamente, numa expressão poética, mas ela responde poeticamente à interpelação contida na teoria, ironizando as estruturas míticas que nela subsistem. O poema reage poeticamente à argumentação kantiana. Ele tira consequências, indica aspectos que permanecem escondidos no registro conceitual do texto kantiano e sublinha ironicamente as estruturas míticas que nele subsistem, propondo uma verdadeira releitura. A leitura desta releitura nos permitirá situar a interrogação sobre o pensamento poético entre a forma teórica do conceito e o trabalho do mito.

2 Orides Fontela. Poesia Completa (org. Luís Dolhnikoff). Sáo Paulo: Hedra, 2015.

3 Cf. exemplos deste método no volume coletivo La lecture insistante. Autour de Jean Bollack. Paris : Albin Michel, 2012. 
De origem modesta, nascida em São João da Boa Vista, no interior do Estado de São Paulo, Orides Fontela obteve desde cedo uma acolhida favorável pela crítica especializada, que a teria "descoberto" em $1965^{4}$, antes mesmo da publicação de seu primeiro livro, Transposição, em 1969. Sua poética sóbria, de versos curtos e enigmáticos, cortados de modo surpreendente, causava espanto por sua novidade em relação à herança modernista dos anos 1920-1940, mas aparecia também como uma alternativa às novas vanguardas concretistas e neoconcretistas do pós-guerra. De fato, é como potência de inovação que a poesia de Orides Fontela foi recebida por Antonio Candido em sua apresentação bastante elogiosa do terceiro livro da poeta, Alba, de 1983:

Um poema de Orides Fontela tem o apelo das palavras mágicas que o póssimbolismo destacou, tem o rigor construtivo dos poetas engenheiros e tem um impacto por assim dizer material de vanguarda recente. Mas não é nenhuma destas coisas, na sua integridade requintada e sobranceira; e sim a solução pessoal que ela encontrou. Parecendo tão inseridos numa certa evolução da poesia moderna, e sendo táo originais como invençấo, os seus versos possuem em geral uma carga de significado que não é frequente 5 .

No final dos anos 1960, Orides cursa Filosofia na Universidade de São Paulo, o que lhe permite aprofundar e desenvolver uma inclinaçấo especulativa que aparecia já em seus primeiros poemas. Entretanto, seu interesse pela filosofia não desemboca numa carreira universitária, mas se reflete efetivamente na forma de sua obra, fazendo dela uma espécie de poeta-filósofa - outra singularidade na tradição poética brasileira. Ora, esta relação importante com a filosofia aparece raramente sob a forma da citação ou da referência explícita, mas se inscreve mais frequentemente na fatura enigmática e intertextual dos poemas, que se configuram em torno de certas problemáticas teóricas: a linguagem e o fazer poético, o mito, o tempo, éros e a questão da liberdade, entre outros temas também tradicionalmente filosóficos.

"Kant (relido)", que me proponho a ler, é um dos raros poemas de Orides que se refere explicitamente à obra de um filósofo. Entretanto, não se trata de uma citação, mas do deslocamento poético de uma passagem frequentemente citada da conclusão da Crítica da razão prática. Ele aparece no volume Rosácea, de 1986, que reúne poemas de juventude então ainda inéditos e textos novos.

\footnotetext{
4 Segundo conta Luís Dolhnikoff na introdução ao volume de suas obras completas, Davi Arrigucci Jr. a teria "descoberto" em 1965, através de um poema publicado no jornal de sua cidade, engajando-se em seguida na edição de seu primeiro livro. $C f$. Luís Dolhnikoff, "Introdução", In: Orides Fontela. Poesia completa, op. cit., p.7.
}

5 Candido, Antonio. "Prefácio". In: Orides Fontela, Alba. São Paulo: Roswitha Kempf Editores, 1983. 
Esse livro, publicado pouco tempo depois do sucesso de Alba, que ganhou o Prêmio Jabuti de poesia em 1984, está dividido em cinco séries de poemas intituladas: Novos, Lúdicos, Bucólicos, Mitológicos e Antigos. O poema que aqui nos interessa faz parte da primeira série. Embora seja seguido por outro texto que se refere à tradição filosófica, é significativamente precedido por "Herança", de coloração sobriamente autobiográfica. Nele, a poeta lista alguns objetos bastante modestos, em sua maior parte utensílios de trabalho manual:

\author{
Herança \\ Da avó materna: \\ uma toalha (de batismo) \\ Do pai: \\ um martelo \\ um alicate \\ uma torquês \\ duas flautas. \\ Da mãe: \\ um pilão \\ um caldeirão \\ um lenço.
}

A proximidade desse poema, cujo teor autobiográfico contrasta com a sobriedade e a concisão da expressão, que nem sequer deixa lugar para a emergência da primeira pessoa, quase sempre anti-liricamente evitada por Orides Fontela, nos incita a problematizar o "eu" que "Kant (relido)" coloca ostensivamente em cena:

\author{
Kant (relido) \\ Duas coisas admiro: a dura lei \\ cobrindo-me \\ e o estrelado céu \\ dentro de mim
}

Ao fragmentar o decassílabo tradicional, o poema engendra uma variação rítmica significativa, produzindo uma espécie de evidência verbal que se aparenta à dos provérbios e à dos oráculos, embora seja quebrada por uma certa ironia. De fato, o primeiro verso pode ser lido como um decassílabo heroico, ritmado pelas tônicas na primeira, na sexta e na oitava sílabas. A pontuação reforça, entretanto, a cesura que o divide em um trecho de seis sílabas e outro de quatro, acentuado na segunda (a dura lei). O segundo verso, composto por uma única palavra (co/brin/do-me), tem apenas duas 
sílabas, repetindo assim a acentuação do segundo segmento do primeiro verso. $\mathrm{O}$ terceiro retoma a extensão da primeira parte do decassílabo inicial (6 sílabas) retardando a primeira tônica, que aparece apenas na quarta ("e o/ es/tre/la/do/ céu"); porém, se fizermos a elisão entre o artigo e o adjetivo, pode também ser lido como uma redondilha menor acentuada na terceira sílaba. O último verso repete ainda o metro da segunda parte do primeiro (4 sílabas) embora acentue fortemente a primeira sílaba: "den/tro/ de/ mim".

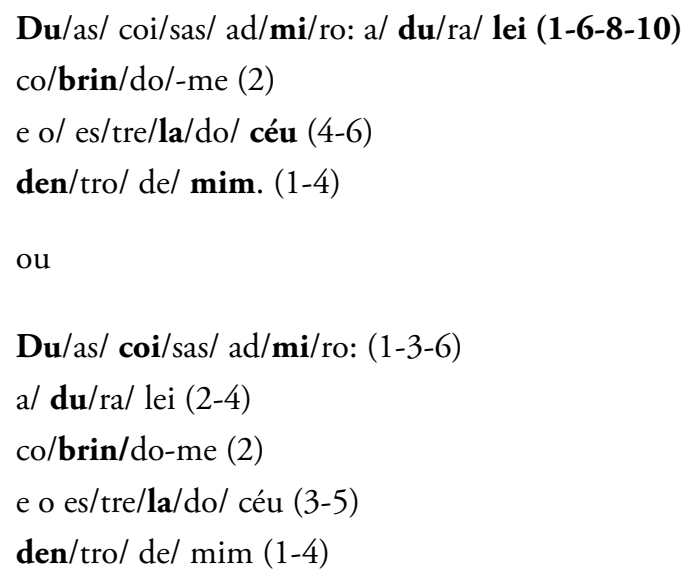

Decompondo o decassílabo tradicional num movimento rítmico que permite variaçôes na cadência da leitura, Orides acentua as palavras "dura", "cobrindo-me" e "dentro". O poema parece efetivamente incitar o leitor a relêlo de outro modo, mimando assim ritmicamente a sugestáo contida no título. Entretanto, para tirar consequências semânticas desse efeito rítmico numa interpretação da releitura proposta pela poeta, precisamos voltar ao texto que ela relê poeticamente para reconstruir o contexto filosófico no qual ele aparece.

\section{O texto relido}

A frase que o poema retoma é frequentemente citada justamente porque constitui uma espécie de exceção na qual, ao final de sua obra, Kant deixa de lado a argumentaçáo conceitual para se exprimir, excepcionalmente, de um modo que pode ser qualificado como lírico: "Duas coisas enchem o ânimo de crescente admiração e respeito, veneração tanto mais renovada quanto com mais frequência e aplicação delas se ocupa a reflexão: sobre mim o céu estrelado, em mim a lei moral"'.

6 E. Kant. Crítica da razão prática (tradução e prefácio de Afonso Bertagnole). Ebooks Brasil, 2004, p. 307(A 289). 
A lei moral que, de acordo com Kant, constitui uma exigência interna não é uma prescrição normativa. Ela corresponde ao postulado segundo o qual cada conduta ética deve repousar sobre a autonomia da razão humana, e portanto sobre a autodeterminação de sua vontade tomada como fim absoluto, o que implica a exigência racional de que todo ser dotado de razão seja sempre tomado como um fim em si mesmo, e jamais reduzido a um mero meio. Assim, de acordo com Kant, a condição de possibilidade de toda responsabilidade moral é a ideia de liberdade, compreendida como a possibilidade de autodeterminaçáo absoluta da vontade segundo uma exigência universal da razão em detrimento do interesse ditado por preferências e inclinaçóes pessoais, assim como por contingências e limitações naturais e sociais. Neste sentido, a argumentação kantiana é circular: a lei moral, imperativo categórico da razão prática, repousa sobre a ideia de liberdade; e a liberdade, que conhecemos a priori apenas como postulado sem que seja possível fazer dela um objeto de experiência, é a condição da lei moral.

Segundo Kant, embora a ideia de liberdade constitua a pedra angular na edificação do sistema da razão pura, pois permite a articulação entre o domínio teórico de conhecimento da natureza e o domínio prático da moralidade, é impossível dar um exemplo de sua aplicação empírica. Conhecemos sua possibilidade a priori apenas como um postulado sobre o qual se fundam todas as ideias da razão, mas nunca como efetivação concreta na experiência.

Na passagem citada, que corresponde à frase "relida" por Orides Fontela, o paralelo entre o céu estrelado "sobre mim" e a lei moral "em mim" corresponde a uma dupla consciência: a de "minha" existência física insignificante face à imensidão irrepresentável do real e a de "minha" responsabilidade moral. Ora, segundo Kant, esta última "começa em meu invisível eu, na minha personalidade, expondo-me em um mundo que tem verdadeira infinidade, porém que só resulta penetrável pelo entendimento e com o qual eu me reconheço (...) em uma conexão universal e necessária, não apenas contingente [...]"7. É essa segunda "visão" que me revela a independência de minha própria vida intelectual em relação ao mundo sensível. Porém, segundo Kant, é ainda esta que, escapando ao domínio das leis da natureza, permite precisamente pensar sua própria conexáo com a natureza pela pressuposição do acordo entre as faculdades de conhecer e o real.

Entretanto, na frase citada, a primeira pessoa não remete apenas a uma consciência lógica, mas acolhe também os sentimentos e a capacidade reflexiva de um indivíduo dotado igualmente de existência física - capaz, portanto, de estabelecer uma relação simbólica entre uma representação sensível do espaço que o cerca e uma ideia racional. Além disso, é significativo que, no parágrafo

7 Ibidem. 
seguinte, Kant faça uma advertência contra a astrologia, que estabelece uma relação mágica entre a esfera moral e a observação do céu. A representação que ele procura esboçar aqui a partir do paralelismo retórico entre as duas visóes - a do céu estrelado acima de mim a da lei moral em mim - náo quer ser confundida com o mundo do mito, mesmo que também náo pertença nem ao domínio teórico, nem ao prático. Trata-se simplesmente de uma imagem para a reflexão, de uma representação estética que abre perspectivas ao pensamento. Assim, esta passagem conclusiva da Crítica da razão prática antecipa em mais de um sentido a Crítica da faculdade do juizo, na qual Kant aborda o campo do sensível e analisa os juízos estéticos puros, confrontandose ao problema da reflexão.

Dessa forma, é justamente a Crítica da faculdade do juizo que tematiza o modo de apresentaçáo da ideias da razáo, propondo uma analogia entre o Belo e a Lei Moral. No contexto dessa argumentação, que se encontra no $\$ 59$ da Analítica do sublime, intitulado "A Beleza como símbolo da moralidade", Kant distingue as noçóes de conceito (do entendimento) e de ideia (da razão) e examina detidamente o modo pelo qual podemos apresentá-los ou expô-los.

Segundo Kant, os conceitos do entendimento podem ser apresentados diretamente pelos exemplos ou esquemas através dos quais expomos sua realidade objetiva. Assim, um conceito puro do entendimento, como o de triângulo, pode ser apresentado através da fórmula matemática que lhe serve de esquema e um conceito empírico, com o de gato, pode ser exposto através de exemplos. Entretanto, as ideias da razão - mesmo que remetam àquelas questóes fundamentais que não podemos deixar de colocar mas que, ao mesmo tempo, somos incapazes de responder - não constituem objetos do conhecimento. Tais ideias, como a de liberdade, ou a de verdade, podem (e devem) apenas ser pensadas, pois fundamentam moral e conhecimento, mas não é possível conhecê-las objetivamente. No entanto, Kant afirma que podemos apresentá-las de modo simbólico, isto é, através de construçôes poéticas complexas que se articulem com a esfera conceitual.

Ora, em seus Paradigmas para uma metaforologia, publicados pela primeira vez em 1960, o pensador alemão Hans Blumenberg propóe uma releitura significativa dessa passagem da Crítica da faculdade do juizo. Explicitando a dimensão necessariamente metafórica dos textos filosóficos, e mesmo daqueles que pretendem a sistematicidade e a determinaçáo conceitual mais estrita, ele empreende pesquisas históricas sobre as metáforas que se articulam aos grandes questionamentos filosóficos. Mais tarde, já nos anos 1970, ele sugere uma origem comum para filosofia e poesia na esfera das correlaçóes não determináveis do pensamento especulativo: a esfera da "não conceitualidade". 
Orides Fontela certamente estudou Kant quando cursou Filosofia, na virada dos anos sessenta para os setenta, mas não é verossímil que tenha assistido muitas aulas sobre Cassirer e nem pode ter tido conhecimento da interpretação da problemática da representação simbólica proposta por Blumenberg, assim como dos desenvolvimentos sobre a esfera da "náo conceitualidade" por ele propostos, já nos anos 1970. O autor só viria a ser recebido no Brasil bem recentemente e, no final dos anos 1960, os departamentos de Filosofia se ocupavam sobretudo da recepção de Heidegger. Entretanto, num depoimento escrito, Orides se pronuncia sobre a filosofia e sobre sua relação com a poesia em termos que se distanciam consideravelmente de uma ontologia da linguagem de inspiração heideggeriana e poderíamos aproximar de algumas consideraçóes de Cassirer e de Blumenberg, que retomam perspectivas kantianas:

Fruto da maturidade humana, [a filosofia] emerge lentamente da poesia e do mito, e inda guarda as marcas de co-nascença, as pegadas vitais da intuição poética. Pois ninguém chegou a ser cem por cento lúcido e objetivo, nunca. Seria inumano, seria loucura e esterilidade. Bem, aí já temos uma diferença básica entre poesia e filosofia - a idade, a técnica, não o escopo. Pois a finalidade de entender o real é sempre a mesma, é "alta agonia" e "difícil prova" que devemos tentar para realizar nossa humanidade. ${ }^{8}$

Nesta conversa, Orides aponta uma origem comum à poesia, "arcaica como o verbo", e à filosofia, "fruto da maturidade humana", na interrogação diante do que ela aqui nomeia "o real", mas que podemos também aproximar do que Cassirer chama de espaço, isto é, o que nos cerca, aquilo no qual nos encontramos e o que também produzimos segundo diferentes modos de relação: conceitual, estético ou mítico. Ora, a poeta afirma não apenas que o modo de relação com o real característico da filosofia surge da poesia e do mito, mas também que esse modo filosófico de visar guarda os "vestígios vivos da intuição poética", os quais se encontram em suas origens. Isso nos permite compreender a orientação geral de sua releitura poética de Kant para retornar ao poema do qual partimos e insistir em sua leitura - e na releitura que ele propóe.

Como vimos, o poema destaca ritmicamente algumas palavras e inverte a estrutura da frase de Kant, sugerindo uma imagem erótica clara, embora bastante sublimada. Qualificada de "dura", termo que não aparece na formulação kantiana, a lei moral que, de acordo com a Crítica da razão

8 Orides Fontela, "Sobre poesia e filosofia - um depoimento", In: Gustavo de Castro. O Enigma Orides. São Paulo: Hedra, 2015, p. 219. 
prática, repousa sobre a liberdade, "cobre" um "eu lírico" discretamente indicado pelo "me" e pelo "mim". Atípico na poética de Orides Fontela, em que o sujeito é frequentemente elidido", o "eu lírico" aparece aqui em voz ativa ("admiro") e passiva ("me, mim"), mas se esconde sob a voz do filósofo numa enunciação que poderia passar por uma citação, não fosse a advertência contida no título. Relida por Orides, essa primeira pessoa que, no próprio texto kantiano, já não poderia mais passar por transcendental, aparece em sua plena corporeidade. E mostra-se feminina, pois não apenas abre-se à "dura lei" que se coloca sobre ela, cobrindo-lhe no sentido sexual do termo, mas também engendra "o estrelado céu" dentro de si.

Invertendo a ordem dos termos e insistindo ritmicamente em certas palavras, Orides Fontela opera uma espécie de subversão na frase de Kant para esboçar uma imagem erótica, reanimando os "vestígios vivos da intuição poética" no interior do texto filosófico. A imagem revela, efetivamente, as ressonâncias míticas da formulação kantiana, remetendo-nos ao mito de Gaia e Uranos, apresentado por Hesíodo no inicio da Teogonia. Gaia, a terra, gera sozinha Uranos, o céu estrelado, que em seguida a recobre completamente, fecundando-a. E assim, Gaia engendra uma série deuses e titấs que permanecem dentro dela, pois Uranos a cobre incessantemente sem deixar espaço para o nascimento dos filhos. Para que Gaia possa parir, será preciso que o filho mais jovem, Cronos, o tempo, castre o próprio pai. E da semente de Uranos, caída na espuma do mar, nasce também Afrodite, a deusa da beleza.

As conotaçóes eróticas e as ressonâncias míticas do poema ironizam a afirmação poética de Kant, aprofundando sua plurivocidade. Na formulação kantiana, a imagem perceptiva do céu estrelado funciona como uma representação simplesmente estética ou reflexiva do acordo entre nossas faculdades de conhecimento e o real - acordo que surge da segunda visão, interna. O respeito da lei moral "em mim" é assim comparado à admiração diante da imensidão ordenada e harmônica do firmamento "sobre mim", isto é, ao respeito diante de uma representação reflexiva de uma finalidade da natureza.

No poema de Orides, o esquema se inverte: o "estrelado céu” está "dentro de mim" e, "cobrindo-me" num longo gerúndio, encontramos a "dura lei", isto é, a lei moral que funda e se funda sobre a liberdade. A plurivocidade do poema, bem mais aberta do que a da frase de Kant, nos leva a fazer conjecturas sobre os deslocamentos metafóricos operados pela poeta em sua releitura do texto filosófico. Nele, o céu estrelado não está "sobre mim", mas

\footnotetext{
9 Para um levantamento da elisão da primeira pessoa no conjunto da obra poética de Orides Fontela, $c f$. "Um panorama do sujeito eclipsado". In: Roberta Andressa Villa Gonçalves. Entre potência e impossibilidade: um estudo da poética de Orides Fontela, p.43-54. Dissertação de mestrado defendida no Programa de pós-graduaçáo em Literatura Brasileira da USP.
} 
se encontra no interior do eu lírico que aparece, portanto, como uma nova Gaia engendrando Uranos. Mesmo que muito indireta, a alusão ao mito cria um paralelo entre a imagem fálica da "dura lei" e a representação do "céu estrelado" que, não mais se referindo à percepção sensível do espaço exterior ao "eu", constitui o que identificamos como uma "predicação impertinente", para retomar a fórmula usada por Ricoeur ao caracterizar a metáfora. Embora o trabalho da semelhança aí opere, não se trata de uma analogia que se poderia resolver numa substituição de termos, mas de um movimento complexo que nos leva da argumentação conceitual à intriga mítica e do mito novamente ao conceito. Vejo-me assim incitada a enunciar hipóteses interpretativas, produzindo ainda releituras da releitura proposta.

Talvez o céu estrelado de Orides seja uma metáfora para a beleza que, segundo Kant, corresponde ela mesma à metáfora da lei moral em nós. Se seguimos essa via interpretativa, devemos considerar que a forma bela, o próprio poema, se encontra em gestação no interior do "eu" - e a questão então se desloca: estaria no interior de sua criadora ou do processo de sua leitura?

No poema, o "estrelado céu" não pode corresponder literalmente à realidade do espaço exterior, como em Kant, pois está "dentro de mim", apresenta-se assim explicitamente como metáfora. Representação metafórica da própria beleza que, segundo Kant, é ela mesma metáfora da lei moral em nós? Se seguimos esta pista interpretativa, devemos considerar que a forma bela, simbolizada na própria forma do poema, não está fora, mas se encontra numa espécie de gestação, e a interrogação assim se desloca: em gestação "dentro" da criação poética ou do processo de leitura do poema?

Ou quem sabe, em sua imensidão infinita que aponta justamente para os limites de nossa capacidade de pôr em imagem, talvez o estrelado céu simbolize aqui mais propriamente a desmesura do sublime, que, ao mesmo tempo, alimenta e coloca em xeque a força e o desejo de dar forma. Em todo caso, o poema aponta o caráter fecundante da "dura lei", isto é, da esfera da liberdade, onde constelaçóes são ideias.

Evocando discretamente o mito de Gaia e Uranos na inversão irônica da frase de Kant, a poeta inventa uma afinidade entre as figuras da "dura lei" e do "estrelado céu", entre a liberdade que fecunda e a gestação que constitui a fatura e a leitura do poema, ambas releituras. 
BLUMENBERG, Hans. Teoria da não-conceitualidade. Ttradução e introdução de Luiz Costa Lima. Belo Horizonte: Editora UFMG, 2013.

CANDIDO, Antonio. "Prefácio”. In: Fontela, Orides. Alba. São Paulo: Roswitha Kempf Editores, 1983.

CASSIRER, Ernst. "Espace mythique, espace esthétique et espace théorique" (tradução de Christian Berner) In: Ecrits sur l'art, Oeuves XII. Paris: Cerf, 1995.

CASSIRER, Ernst. "Le problème du symbole et le système de la philosophie". Tradução de Éric Dufour. In: Marc de Launay (org.) Néo-kantismes et théorie de la connaissance. Paris: Vrin, 2000.

FONTELA, Orides. Poesia Completa. Org. Luís Dolhnikoff. São Paulo: Hedra, 2015.

FONTELA, Orides. Sobre poesia e filosofia - um depoimento. In: Castro, Gustavo de. O Enigma Orides. São Paulo: Hedra, 2015.

GONÇALVES, Roberta Andressa Villa. Entre potência e impossibilidade: um estudo da poética de Orides Fontela. Dissertação de mestrado defendida no Programa de pós-graduação em Literatura Brasileira da USP.

HESÍODO. Théogonie. In: Théogonie, Les travaux et les jours, Le Bouclier. Ttradução bilíngue de Paul Mazon. Paris: Les Belles Lettres, 2002.

KANT, Emanuel. Crítica da razão prática. Tradução e prefacio de Afonso Bertagnole. Rio de Janeiro: Ebooks Brasil, 2004

KANT, Emanuel. Crítica da faculdade de julgar (tradução de Fernando Costa Mattos). Petrópolis: Editora Vozes, 2016.

Patrícia Lavelle. É professora do Departamento de Letras da PUC-Rio, atuando no Programa de Pós-graduação em Literatura, Cultura e Contemporaneidade. Doutora em filosofia pela École des Hautes Études en Sciences Sociales de Paris, tem livros de ensaios publicados na França e no Brasil e suas pesquisas problematizam as relações entre criação literária e reflexão filosófica. Como poeta, publicou Migalhas metacríticas (coleção megamíni, 7Letras, 2017), Bye bye Babel (7Letras, 2018) e, com Paulo Henriques Britto, organizou O Nervo do poema - Antologia para Orides Fontela (Relicário, 2018).

E-mail: patrícia.g.lavelle@gmail.com 